Association for Information Systems AIS Electronic Library (AISeL)

International Research Workshop on IT Project

International Research Workshop on IT Project

Management 2007

Management (IRWITPM)

December 2007

\title{
An Experimental Investigation of Factors Influencing Perceived Control over a Failing IT Project
}

Arpan Jani

University of Wisconsin

Follow this and additional works at: http://aisel.aisnet.org/irwitpm2007

\section{Recommended Citation}

Jani, Arpan, "An Experimental Investigation of Factors Influencing Perceived Control over a Failing IT Project" (2007). International Research Workshop on IT Project Management 2007. 5.

http://aisel.aisnet.org/irwitpm2007/5

This material is brought to you by the International Research Workshop on IT Project Management (IRWITPM) at AIS Electronic Library (AISeL). It has been accepted for inclusion in International Research Workshop on IT Project Management 2007 by an authorized administrator of AIS Electronic Library (AISeL). For more information, please contact elibrary@aisnet.org. 


\title{
An experimental investigation of factors influencing perceived control over a failing IT project
}

\author{
Arpan Jani \\ College of Business and Economics \\ University of Wisconsin - River Falls \\ e-mail: arpan.jani@uwrf.edu
}

\begin{abstract}
Some failing IT projects may exhibit the characteristics of escalation of commitment as managers may continue to pour more resources into failing projects. If project managers continue to believe that the project is under their control, they may be more likely to recommend continuation of a failing project. While research in IT project management has identified many risk factors, little attention has been paid to the impact of these risk factors on decision making in projects. An experiment using a computer simulated task investigated the influence of self-efficacy and project risk characteristics on perceived control over a failing IT project. The study found that participants with higher task-specific self-efficacy were likely to perceive greater control over a failing project even when the project risk factors were less within the control of the participants.
\end{abstract}

\section{Keywords}

IS Project Control, IS Project Management Methods and Tools.

\section{INTRODUCTION}

Academic researchers (Drummond, 1996; Keil, 1995) as well as journalists (Kindel, 1992; Ellis, 1994) have documented several cases of 'escalation of commitment' in IT projects where IT projects were not terminated despite showing signs of failure. Keil and Mann (1997) had found in a survey of IS auditors that about 30-40\% of IT projects showed some degree of project escalation. Such projects may eventually be abandoned at a much later stage after even more resources are poured into the project. A study by Ewusi-Mensah and Przasnyski (1991) indicated that 35\% of the failing IT projects were abandoned only after the implementation stage. If a decision to discontinue the project had been taken earlier, it could have saved considerable resources. Several theoretical perspectives such as self-justification theory (Staw, 1981), prospect theory (Whyte, 1986), agency theory (Harrison and Harrell, 1993) and hypotheses such as the "sunk cost effect" (Arkes and Blumer, 1985) and "project completion effect" (Boehne and Paese, 2000) have been offered to explain escalation of commitment to failing courses of action. The risk perception perspective (Keil et al., 2000a; Keil et al., 2000b) suggests that if project managers perceive the project risks accurately, they would be more likely to recommend discontinuation of failing projects. The self-efficacy hypothesis (Whyte, Saks, and Hook, 1997; Whyte and Saks, 2007) suggests that decision makers with higher self-efficacy are more likely to persist with failing projects. If project managers continue to believe that the project is under their control they would be more likely to recommend continuation of failing projects.

Research on IT project management has paid significant attention to identification and classification of various risk factors. However, very little attention has been paid to understand the impact of various risk factors on the judgment and decisions made by project managers. The objective of the study reported in this article was to understand whether project risk characteristics and individual self-efficacy influenced the perceived control over the project.

\section{BACKGROUND}

Researchers in software risk management have classified project risk factors into various categories (Barki, Rivard, and Talbot, 1993; Ropponen and Lyytinen, 2000; Wallace and Keil, 2004; Wallace, Keil, and Rai, 2004). Keil and his colleagues have defined project risk characteristics based on the perceived degree of managerial control or the 'sphere of influence' over the risk factor (Keil, Cule, Lyytinen and Schmidt, 1998; Tiwana and Keil, 2004). Keil et al. (1998) found that the risks that were considered most important by project managers were often not under their direct control. This paper classifies project risk factors into endogenous and exogenous risk factors based on the degree of managerial control over the risk factors. Exogenous risk factors are variables or events linked to external factors that can influence the project outcomes negatively but are not under the direct control of the project manager. For example, risk factors such as environmental factors like governmental regulations, or change in business environment, change in project scope, lack of senior management commitment are external to the project environment and are less within the control of the project manager. Endogenous risk factors are variables or events linked to project's internal factors that can influence the project outcomes negatively but are 
under the direct control of the manager, such as project team morale, employee productivity, staffing level and experience and so forth.

While executing a project, project managers' perceived control over the project would be based on the actions taken in the past and outcomes achieved for the project. Decision makers may exhibit self-serving bias such that they may attribute success to their own efforts whereas may attribute failure to external factors. Based on the type of risk factor that may be present for a project, the project managers may evaluate the action-outcome information differently in case of failing projects. When a project is dominated by exogenous risk factors, project managers could easily attribute the negative outcomes to exogenous risk factors not within their control and may not perceive the negative outcomes to be directly related to their own actions. When a project is dominated by endogenous risk factors, project manages may attribute the outcomes to their own actions to a greater degree.

Hence it can be hypothesized that, other things being equal,

H1: Project managers executing failing projects with endogenous risk factors would likely perceive greater degree of control over the project as compared to project managers executing failing projects with exogenous risk factors.

Self-efficacy is another factor that could influence managers' perceived control over the project. Self-efficacy is a personal judgment about how well one can perform in a given task situation or a domain. Past experience greatly influences selfefficacy (Bandura, 1997) as successful past experiences with a task domain can build greater self-efficacy whereas unsuccessful past experiences can erode ones self-efficacy. Self-efficacy may lead to generalization of past actions-outcomes to a new situation even when it may not be applicable directly. Experienced managers may develop a high sense of selfefficacy by their past successes, which may lead them to believe that it will also be applicable to the new situation. As Staw and Ross (1987, p. 69) observed "It's tough for managers with good track records to recognize that a certain course isn't satisfactory risk - that things aren't once again going to turn their way." Thus, self-efficacy could lead to biased assessment of the perceived control over the project.

It can be hypothesized that, other things being equal,

H2: While executing failing projects, project managers with higher self-efficacy would be likely to perceive greater degree of control over the project as compared to project managers with lower self-efficacy.

\section{RESEARCH METHOD}

An experiment was conducted using a computer simulated software project serving as an interactive, dynamic task. Experiments that use micro-worlds or dynamic task environments provide certain advantages as compared to traditional experiments that use static tasks or field based studies (Brehmer and Dorner, 1993):

- Compared to the static tasks used in experiments, dynamic task environments provide greater task realism i.e. greater correspondence with the actual task, as well as greater degree of experimental realism i.e. greater degree of participant involvement (DiFonzo, Hantula, and Bordia, 1998).

- Compared to field studies, one can achieve greater degree of control in isolating other factors that may also influence the variables of interest. For example, in field studies it would be difficult to isolate the effects of various categories of risk factors associated with the project on the judgment and decisions made by project managers.

- The investigator can easily collect rich data about the information being viewed by the participants, the decisions made, the decision outcomes, and how the participants assessed the situation over time. Since a series of judgments and decisions are being made, one can investigate whether the biased evaluation of a situation persists over time. It would be quite difficult to collect such data in field studies during the execution of a real-life project. Many times one may have to rely on retrospective accounts.

\section{Experimental Design}

The experimental design was $2 \times 2 \times 2 \times 4$ mixed factorial design with between-subjects manipulations of project risk factors (High/Low controllability) and initial task-specific self-efficacy (High/Low). Undergraduate and graduate students participated in the experiment in the first phase and experienced project managers participated in the second phase. Thus, participant category (students/project managers) served as a blocking factor. Participants played the role of a software project manager and made staffing decisions for a simulated software project. As participants made project decisions, they were provided increasingly negative feedback about project progress indicating that the project could be on the path of failure. This served as a within-subjects factor since the same feedback was provided to all participants that were at the same stage.

Initial task-specific self-efficacy was manipulated in the experiment by providing participants with a successful or unsuccessful task experience with a similar task before they worked on the main task. Controllability of project risk factors 
was manipulated by assigning one of the two task scenarios to participants. While working on the main task, participants were periodically asked to fill out a project assessment report in the form of a structured questionnaire. Repeated measures (4 stages) were taken of participants' assessment of project status, their perceived degree of control over the project, their assessment of project risk, and their commitment to the (failing) project. The perceived degree of control over the project was measured with a single item scale.

\section{Procedure}

20 undergraduate students, 16 graduate students, and 35 practicing managers participated in the study. All student participants were familiar with the software development lifecycle and with the basic concepts of project management, either through the course work or having worked on software projects. After providing their consent participants began the experiment by reading the background description about the project situation and then completing a tutorial that explained how the simulated project worked. Participants then worked on one of the two types of practice tasks that served as an experimental manipulation for initial task-specific self-efficacy (TSSE). After working on the practice task, the participants worked on one of the two types of the main tasks that embedded the experimental manipulation for project risk factors. Participants were randomly assigned to one of the four practice task-main task combinations.

The practice task was designed to manipulate the initial task-specific self-efficacy (TSSE) beliefs of the participants. Participants assigned to the successful practice task scenario were given positive feedback during their task performance that they had been keeping the project on track with respect to cost and schedule and had managed to complete the practice project on time and within budget. Participants assigned to the unsuccessful practice task scenario were provided feedback during their task performance that they had been falling behind schedule and in the end could not complete the project on time and within budget. It was expected that participants would relate their previous task experience to the next task assigned to them. Thus, participants who worked on a successful practice task before working on the main task could be expected to have higher initial task-specific self-efficacy (TSSE), i.e. greater degree of confidence in their ability to complete the next project successfully, as compared to participants who had found that they could not manage to complete the practice task successfully. Manipulation check measures taken immediately after the practice task confirmed that the manipulation of selfefficacy beliefs was successful.

After completing the practice task, participants worked on the main task, which was to execute a simulated project with a budget of $\$ 3$ million scheduled to be completed within 60 weeks. Participants could work on one of the two task scenarios that embedded an endogenous risk factor or an exogenous risk factor. Participants assigned to the Endogenous risk factor scenario were told that the project team members were not experienced with the technology domain. This was an endogenous risk factor directly in control of the participants. Participants could hire experienced staff and provide training to staff to compensate for their lack of experience. Hiring staff and providing training are managerial levers directly in control of most project managers. Participants in the endogenous risk factor scenario had indeed provided more training to their staff $(\mathrm{M}=$ 179.43 hours, $\mathrm{SD}=129.75)$ as compared to participants in the exogenous risk factor scenario $(\mathrm{M}=130$ hours, $\mathrm{SD}=116.42)$ which was significant at $\mathrm{p}<.05$ level. Participants assigned to the Exogenous risk factor scenario found that the project scope kept increasing over the course of the project and they could not restrict the project scope. Participants had to simply accept the revised project scope. Scope creep or scope change is a risk factor generally considered less within the control of the project managers.

Participants made staffing decisions (acquiring and releasing staff, training provided) for twelve five-week periods. Participants could monitor project status at the end of each five week period and then make subsequent decisions. At the end of every 15 weeks of simulated time or three decision periods, participants had to provide their overall assessment of the project and their recommendation to the (hypothetical) project steering committee whether the project should be continued or not. As the project progressed over time, participants received increasingly negative feedback indicating that the project was deviating from the planned trajectory and was on the path of failure. All participants at the same stage of the project were provided the same negative feedback about project progress irrespective of their previous decisions. This was done to control for the effects of project status information provided to the participants on the assessments made. In this way the differences in the assessments made by the participants could be attributed only to the experimental manipulations and not to the differences in project status information available to them.

\section{RESULTS}

The data collected about the periodic assessments made by participants was analyzed to address the research question posed earlier. As part of project assessment provided by the participants at each review stage, participants responded to a single item on a scale of 0-100 that measured their perceived degree of control over the project. A response of 0 would indicate no

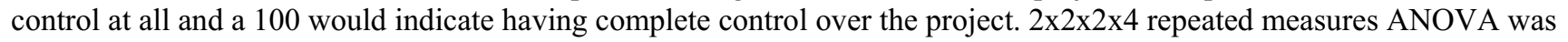


performed with Initial TSSE (High/Low) and Project Risk Factors (Endogenous/Exogenous risk factors) as between-subjects factors, Participant Category (Students/Project Managers) as a blocking factor and Project Review Periods as the withinsubject factor. The analysis revealed that there were significant main effects of time on perceived project control i.e. participants' perceived significantly lesser degree of control over the project as the project progressed over time. There was no time $\mathrm{x}$ group interaction.

\begin{tabular}{|c|c|c|c|c|c|}
\hline Source & $\begin{array}{l}\text { Type III } \\
\text { Sum of } \\
\text { Squares }\end{array}$ & df & $\begin{array}{l}\text { Mean } \\
\text { Square }\end{array}$ & $\mathbf{F}$ & Sig. \\
\hline Intercept & 822921.46 & 1 & 822921.46 & 774.31 & .000 \\
\hline Initial TSSE & 10542.75 & 1 & 10542.75 & 9.92 & .002 \\
\hline Project Risk Factors & 5003.47 & 1 & 5003.47 & 4.71 & .034 \\
\hline Participant Category & 38.13 & 1 & 38.13 & .04 & .850 \\
\hline Initial TSSE $*$ Project Risk Factors & 9104.46 & 1 & 9104.46 & 8.57 & .005 \\
\hline Error & 69080.28 & 65 & 1062.77 & & \\
\hline
\end{tabular}

Table 1. Test of Between-Subjects Effects on Perceived Project Control

The main effects of participants' initial TSSE and project risk factors respectively were significant, thus supporting hypotheses $\mathbf{H 1}$ and $\mathbf{H 2}$. The interaction between initial TSSE and project risk factors was significant as well. Participants with higher initial TSSE perceived greater control over the project compared to participants with lower initial TSSE when working on the task with exogenous risk factor scenario. There were no significant differences between students and project managers in their perceived degree of control over the project across time.

\section{DISCUSSION}

In this section the implications of the results are discussed with respect to the objectives of the study, the advantages of the research method employed, and the limitations of the study. While most laboratory studies on escalation of commitment have used static tasks, this study employs a dynamic task scenario that enables investigation of how decision makers assess the situation over time. Further, laboratory studies that have investigated decision making in failing projects have predominantly used students as participants. This study uses both students and practicing managers as it allows comparison between the two groups and enables greater generalization of results. Further, the student sample was not naïve with respect to the task employed but had conceptual understanding of the software development lifecycle and project management principles. While it may be difficult to obtain data on how project managers evaluate project progress during execution, computer simulation based experiments provide the opportunity to investigate judgment and decision making in 'real-time'. On the other hand, it was not possible to recruit a large number of study participants, particularly practicing project managers, since this study employed a richer, dynamic task scenario and also had used participants who were knowledgeable about project management.

In their assessment of the degree of control over the project, the participants were influenced both by the project risk factors and initial task specific self-efficacy. In reality, participants had no control over the project outcomes as the feedback was manipulated in the experiment to create the scenario of a failing project. Participants who had higher initial TSSE perceived greater degree of control over the failing project when facing an exogenous risk factor scenario as compared to participants who had lower initial TSSE. There were no significant differences when the participants worked on endogenous risk factor scenario irrespective of their initial TSSE. This means that managers with a successful past track record when facing project risks that are less within their control may still continue to assess the project to be within their control when the risk materializes and the project shows signs of failure. Further, the way project risks are classified before the project begins will influence how the project outcomes are interpreted. Even though past experience with similar projects can be informative when making assessments for new projects, project managers should not allow an undue influence on ones judgment about how much control one has over the project.

\section{CONCLUSION}

The research contributes to the literature on IT project management in two ways. Whereas most studies investigating escalation of commitment in IT projects have used static tasks where participants did not get the opportunity to revise their judgment (see for example, Keil, Truex, and Mixon, 1995; Keil et al., 2000a; Keil et al., 2000b), this study uses a dynamic 
task scenario. Literature on IT project management has focused on identification and classification of project risk factors. However, the impact of these risk factors on project decision making has not been investigated. Perceived control over the project is a significant factor that could influence the commitment to a failing project. This study investigated the role of project risk factors as well as individual self-efficacy on perceived project control. The study shows how project factors may interact with behavioral factors in influencing decision making in IT projects.

Task-specific self-efficacy was found to influence perceived control over the project. This means that project managers should be careful in assessing their degree of control over the project. Project managers may get heavily influenced by their past success and even when a project is on the path of failure and project risk factors are less within their control, project managers may continue to believe that things are under their control and the project could be turned around. Project managers in such situations could wait longer to determine whether the project should be terminated or not.

\section{REFERENCES}

1. Arkes, H. R., and Blumer, C. (1985) The psychology of sunk cost, Organizational Behavior and Human Decision Processes, 35, 1, 124-140.

2. Bandura, A. (1997) Self-efficacy: The exercise of control, W. H. Freeman and Company, New York.

3. Barki, H., Rivard, S. and Talbot, J. (1993) Toward an assessment of software development risk, Journal of Management Information Systems, 10, 2, 203-225.

4. Boehne, D. M., and Paese, P.W. (2000) Deciding whether to complete or terminate an unfinished project: A strong test of the project completion hypothesis, Organizational Behavior and Human Decision Processes, 81, 2, 178-194.

5. Brehmer, B., and Dorner, D. (1993) Experiments with computer-simulated microworlds: Escaping both the narrow straits of the laboratory and the deep blue sea of the field study, Computers in Human Behavior, 9, 2-3, 171-184.

6. DiFonzo, N., Hantula, D. A. and Bordia, P. (1998) Microworlds for experimental research: Having your (control and collection) cake, and realism too, Behavior Research Methods, Instruments and Computers, 30, 2, 278-286.

7. Drummond, H. (1996) Escalation in decision-making: The tragedy of Taurus, Oxford University Press, Oxford.

8. Ellis, V. (1994) Audit says DMV ignored warning, Los Angeles Times, August 18, pp. A3, A24.

9. Ewusi-Mensah, K. and Przasnyski, Z. H. (1991) On information systems project abandonment: An exploratory study of organizational practice, MIS Quarterly, 15, 1, 67-88.

10. Harrison, P. D. and Harrell, A. (1993) The impact of "adverse selection" on managers' project evaluation decisions, Academy of Management Journal, 36, 3, 635-643.

11. Keil, M. (1995) Pulling the plug: Software project management and the problem of project escalation, MIS Quarterly, 19, 4, 421-447.

12. Keil, M., Truex, D.P. and Mixon, R.(1995) The effects of sunk cost and project completion on information technology project escalation, IEEE Transactions on Engineering Management, 42, 4, 372-381.

13. Keil, M., and Mann, J. (1997) The mature and extent of IT project escalation: Results from a survey of IS audit and control professionals (Part 1), IS Audit and Control Journal, 1, 40-48.

14. Keil, M., Cule, P.E., Lytinnen, K. and Schmidt, R. C. (1998) A framework for identifying software project risks, Communications of the ACM, 41, 11, 76-83.

15. Keil, M., Mann, J. and Rai, A. (2000) Why software projects escalate: An empirical analysis and test of four theoretical models, MIS Quarterly, 24, 4, 631-664.

16. Keil, M., Tan, B.C.Y., Wei, K.K., Saarinen, T., Tuunainen, V., and Wassenaar, A. (2000a) A cross-cultural study on escalation of commitment behavior in software projects, MIS Quarterly, 24, 2, 299-325.

17. Keil, M., Wallace, L., Turk, D., Dixon-Randall, G. and Nulden, U. (2000b). An investigation of risk perception and risk propensity on the decision to continue a software development project, The Journal of Systems and Software, 53, 2, 145157.

18. Kindel, S. (1992) The computer that ate the company, Financial World, March 31, 96-98.

19. Ropponen J., and Lyytinen K. (2000) Components of software development risk: How to address them? A project manager survey, IEEE Transactions on Software Engineering, 26, 2, 98-112.

20. Shapira, Z. (1995) Risk taking: A managerial perspective, Russell Sage Foundation, New York. 
21. Staw, B. (1981) The escalation of commitment to a course of action. Academy of Management Review, 6, pp. 40-64.

22. Staw, B., \& Ross, J. (1987) Knowing when to pull the plug, Harvard Business Review, March-April, 68-74.

23. Tiwana, A., and Keil, M. (2004) The one-minute risk assessment tool, Communications of the ACM, 47, 11, 73-77.

24. Wallace, L., and Keil, M. (2004) Software project risks and their impact on outcomes, Communications of the ACM, 47, 4, 68-73.

25. Wallace, L., Keil, M., and Rai, A. (2004) How software project risk affects project outcomes: An investigation of the dimensions of risk and an exploratory model, Decision Sciences, 35, 2, 289-321.

26. Whyte, G. (1986) Escalation of commitment to a course of action: A reinterpretation, Academy of Management Review, $11,2,311-321$.

27. Whyte, G., Saks, A. M., and Hook. S. (1997) When success breeds failure: The role of self-efficacy in escalating commitment to a losing course of action, Journal of Organizational Behavior, 18, 5, 415-432.

28. Whyte, G., and Saks, A. M. (2007). The Effects of self-efficacy on behavior in escalation situations, Human Performance, 20, 1, 23-42. 